\title{
Elemental Composition of Atmospheric Particulate Matter during 2006 Wet Season at a Rural Background Site in Tanzania
}

\author{
1*MKOMA, S L; ${ }^{2}$ MAENHAUT, $\mathbf{W} ;{ }^{2}$ RAES, N \\ ${ }^{1}$ Department of Physical Sciences, Faculty of Science, Sokoine University of Agriculture (SUA), P.O. Box 3038, Morogoro, Tanzania \\ ${ }^{2}$ Department of Analytical Chemistry, Institute for Nuclear Sciences, Ghent University, Proeftuinstraat 86, B-9000 Gent, Belgium
}

\begin{abstract}
The elemental composition of PM10 was studied during 2006 wet season in a rural background site of Morogoro, Tanzania. A Gent PM10 stacked filter unit sampler with coarse and fine Nuclepore polycarbonate filters, providing fine $(0.4 \mu \mathrm{m})$ and coarse $(8 \mu \mathrm{m})$ size fractions, was deployed. A total of 29 collections were analysed for the PM mass by weighing. A further analysis was performed for 25 elements by particle-induced $\mathrm{x}$-ray emission spectrometry. The results show that the concentrations of the heavy metals were lower than those for the elements of crustal origin. The data from PIXE analysis and enrichment factor (E.F.) calculation, using Fe as a reference of crustal material, showed that for the coarse size fraction, most elements have crustal EFs that are very close to one, while enriched elements (E.F. > 10) like S, Cl, $\mathrm{Zn}, \mathrm{As}, \mathrm{Br}, \mathrm{Pb}$ and $\mathrm{BC}$, predominated in fine (PM2) size fraction (an anthropogenic origin can be suggested for the later). Potassium a well-known indicator for biomass burning was mostly associated with the fine particles (as around $56 \%$ of the PM10 K was in the PM2 size fraction). This suggests that biomass burning was important in Morogoro. Five-day isentropic backward trajectories as determined by the air trajectory HYSPLIT model were computed for Morogoro and the allocated sector of oceanic origin over continental, mainly through Mozambique and Tanzania) was the most common. However, other sectors such as Oceanic, over Madagascar or continental origins were observed. @ JASEM
\end{abstract}

In the rural environment, particulate matter may be generated among others by biomass burning, soil (and road) dusts dispersion and through photochemical reactions involving precursors gases. Among the various species present in the particulate matter, a concern have been on the study of toxic metals such as lead, zinc, copper and on elements of great diffusion in the environment (IPCC, 2007). Few such studies have been done in this part of Tanzania (Mkoma et al., 2009a,b). Because of local and global contamination of these elements and their relative effects on human health, this study aimed to determine the elemental composition of PM10 particles using Particle Induced X-Ray Emission (PIXE) technique for aerosol from a rural background site in Morogoro.

\section{MATERIALS AND METHODS}

The sampling campaign took place during the 2006 wet season (March - April) at the main campus of Sokoine University of Agriculture (SUA). The site is located at 6 ${ }^{\circ} 49^{\prime} 39.7^{\prime \prime} \mathrm{S}, 37^{\circ} 39^{\prime} 48.1^{\prime \prime} \mathrm{E}$, altitude $526 \mathrm{~m}$ above sea level (a.s.l), and is about $200 \mathrm{~km}$ to the west of the Indian Ocean. A total of 29 collections were made with a Gent PM10 stacked filter unit (SFU) sampler, PM10 (Hopke et al., 1997). A detailed description of the site and the sampling protocol are given elsewhere (Mkoma et al., 2009a, b). For Particulate mass measurement, the field blanks and actual samples were weighed before and after sampling with a Mettler MT5 microbalance (sensitivity $1 \mu \mathrm{g}$ ). Before weighing, the filters were conditioned at a relative humidity of $50 \%$ and a temperature of $20{ }^{\circ} \mathrm{C}$ for 24 hours and the weighings were done at these conditions. One quarter of each Nuclepore polycarbonate filter was used to determine black carbon (BC) by a light reflectance technique and 25 elements by particle-induced X-ray emission (PIXE) spectrometry (Maenhaut and Cafmeyer, 1998). However, it should be noted that the PIXE data for the lightest elements $(\mathrm{Na}$ and $\mathrm{Mg})$ are not very reliable because of severe X-ray attention. The data for sodium and magnesium used in this study were obtained from Ion Chromatography (IC) analysis. The reported atmospheric concentrations for the PM10 mass and elements were all corrected for field blanks.

\section{RESULTS AND DISCUSSION}

Concentrations of elements: Table 1 shows the median concentrations and concentration ranges for PM10 mass and various elements in the PM10 size fractions. As can be seen from table 1, higher levels of many major, minor, and trace elements were obtained during the campaign and the median concentration of $\mathrm{As}, \mathrm{Se}, \mathrm{Br}, \mathrm{Rb}, \mathrm{Ba}$ and $\mathrm{Pb}$ were below the detection limit. However, if compared with previous studies (Mkoma et al., 2009b), all elements have their lowest medians in the 2006 wet season campaign than in 2005 dry season campaign. This is mainly ascribed to the increased precipitation in 2006 wet season campaign; besides, the soil is wetter so that there is less dispersal of soil dusts and there is also less biomass burning than in the dry season. The elemental concentration data for Morogoro can be compared with those of other studies in eastern 
Africa. The levels of the measured elements (except $\mathrm{Zn}$ ) are about a factor of 6 higher than those reported by Gatebe et al. (2001) for aerosol samples from a rural site on the slope of Mount Kenya and a factor of $\mathrm{Mn}, \mathrm{Fe}, \mathrm{Ni}, \mathrm{Cu}$, and $\mathrm{Zn}$ than those reported for tradition
3 - 10 higher than for aerosols from Rukomechi, a rural site in Zimbabwe (Nyanganyura et al., 2007). In contrast, the levels at Morogoro are lower by a factor of $2-14$ for elements such as $\mathrm{Si}, \mathrm{Ca}, \mathrm{Ti}$, al villages of Serowe in Botswana (Moloi et al., 2002).

Table 1. Median concentrations and concentration ranges for PM10 mass $\left(\mu \mathrm{g} / \mathrm{m}^{3}\right)$ and all measured elements $\left(\mathrm{ng} / \mathrm{m}^{3}\right)$ in the PM10 fraction during the 2006 wet season campaign

\begin{tabular}{lccccccccccccc}
\hline Species & $\mathbf{P M}$ & $\mathbf{N a}$ & $\mathbf{M g}$ & $\mathbf{A l}$ & $\mathbf{S i}$ & $\mathbf{P}$ & $\mathbf{S}$ & $\mathbf{C l}$ & $\mathbf{K}$ & $\mathbf{C a}$ & $\mathbf{T i}$ & $\mathbf{V}$ & $\mathbf{C r}$ \\
\hline Median & 13 & 131 & 31 & 400 & 740 & 34 & 173 & 92 & 189 & 250 & 35 & 0.62 & $\mathrm{DL}$ \\
Min. & 8.2 & 11 & 12 & 120 & 230 & 21 & 93 & $\mathrm{DL}$ & 110 & 100 & 10 & $\mathrm{DL}$ & $\mathrm{DL}$ \\
Max. & 25 & 730 & 110 & 1160 & 2100 & 52 & 600 & 680 & 350 & 900 & 100 & 2.7 & 1.8 \\
\hline Species & $\mathbf{M n}$ & $\mathbf{F e}$ & $\mathbf{N i}$ & $\mathbf{C u}$ & $\mathbf{Z n}$ & $\mathbf{G a}$ & $\mathbf{A s}$ & $\mathbf{S e}$ & $\mathbf{B r}$ & $\mathbf{R b}$ & $\mathbf{S r}$ & $\mathbf{B a}$ & $\mathbf{P b}$ \\
\hline Median & 4.7 & 370 & 0.27 & 0.89 & 4.4 & 0.25 & $\mathrm{DL}$ & $\mathrm{DL}$ & $\mathrm{DL}$ & $\mathrm{DL}$ & 1.2 & $\mathrm{DL}$ & $\mathrm{DL}$ \\
Min. & 1.4 & 110 & $\mathrm{DL}$ & 0.35 & 2.2 & $\mathrm{DL}$ & $\mathrm{DL}$ & $\mathrm{DL}$ & $\mathrm{DL}$ & $\mathrm{DL}$ & $\mathrm{DL}$ & $\mathrm{DL}$ & $\mathrm{DL}$ \\
Max. & 14 & 1110 & 1.1 & 3.6 & 9.7 & 1.4 & 0.59 & 0.39 & 2.1 & $\mathrm{DL}$ & 3.3 & 7 & 0.98 \\
\hline
\end{tabular}

Fine to PM10 ratios: Average fine to PM10 concentration ratios were calculated for the PM mass and various elements; the results are shown in Fig. 1. The average concentration ratios and associated standard deviations for some anthropogenic metals were mainly present in the fine size fraction. The crustal elements ( $\mathrm{Al}, \mathrm{Si}, \mathrm{Ca}, \mathrm{Ti}, \mathrm{Mn}$, and $\mathrm{Fe}$ ) and the sea-salt elements (Na, $\mathrm{Mg}, \mathrm{Cl}, \mathrm{Sr})$ were predominantly associated with the coarse size fraction. $\mathrm{Cu}$ and $\mathrm{Zn}$ were also mainly associated with the coarse particles. K (a well-known indicator for biomass burning) was mostly associated with the fine particles (in contrast to $\mathrm{Ca}$ ). This suggests that biomass burning was important in Morogoro, as around $56 \%$ of the PM10 K was in the PM2 size fraction.

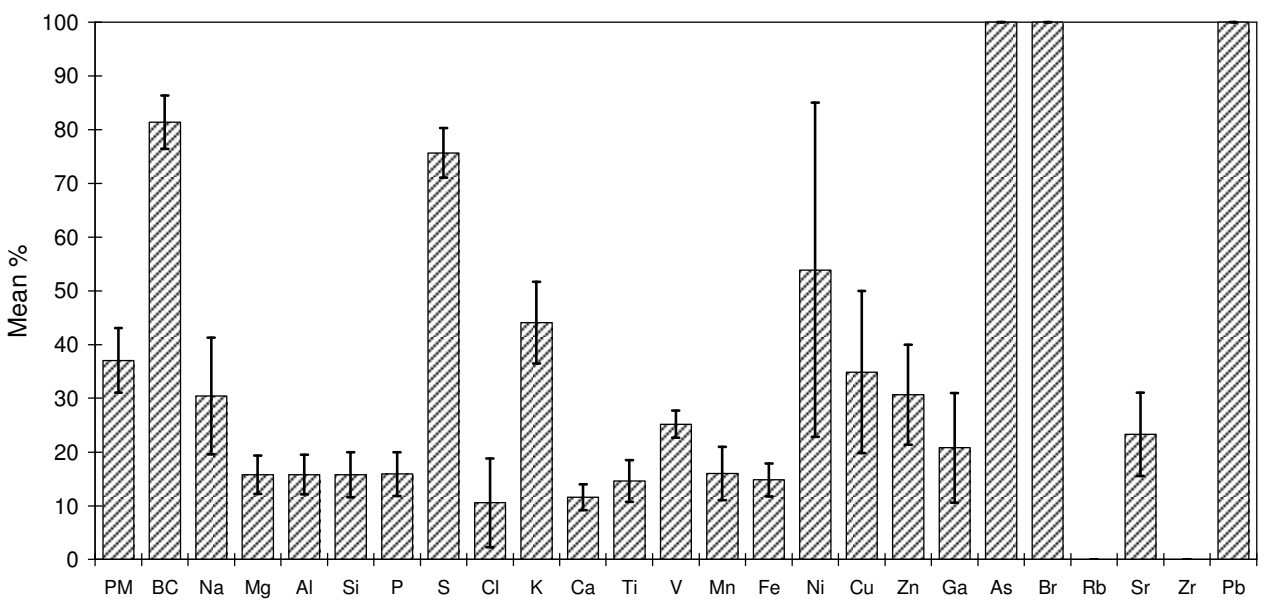

Fig. 1.Mean percentage and associated standard deviation of the PM10 aerosol in the fine (PM2) size fraction for the PM mass and various elements in Morogoro.

Crustal enrichment factors: Median crustal enrichment factors (EFs) for the various elements in the coarse and fine size fractions were calculated relative to the average crustal rock composition of Mason and Moore (1982), with $\mathrm{Fe}$ as reference element:

$$
\mathrm{EF}=\left(\mathrm{X}_{\mathrm{PM}} / \mathrm{Fe}_{\mathrm{PM}}\right) /\left(\mathrm{X}_{\text {crust }} / \mathrm{Fe}_{\text {crust }}\right)
$$

where $\mathrm{X}_{\mathrm{PM}}$ and $\mathrm{Fe}_{\mathrm{PM}}$ are the concentrations of the measured element and $\mathrm{Fe}$ in the aerosol, while $\mathrm{X}_{\text {crust }}$ and $\mathrm{Fe}_{\text {crust }}$ are the concentrations of the measured element and $\mathrm{Fe}$ in average crustal rock composition of Mason and Moore (1982). The calculated EFs are shown in Fig. 2 and Fig. 3; for $\mathrm{BC}$ the ratio to $\mathrm{Fe}$ (instead of the EF) is shown. For the coarse size fraction (Fig. 3), most elements have crustal EFs that are very close to one, thus suggesting that they are attributable mainly to soil dust dispersal. With the exception of $\mathrm{Al}, \mathrm{Cl}$, and $\mathrm{Ca}$, which are slightly more enriched in the coarse fraction, all elements exhibit 
higher EFs in the fine size fraction (Fig. 2) during the campaign. For the strongly enriched elements (EFs > 10 in the fine size fraction) like $\mathrm{S}, \mathrm{Cl}, \mathrm{Zn}, \mathrm{As}, \mathrm{Br}$, and

$\mathrm{Pb}$, and also for $\mathrm{BC}$ an anthropogenic (pyrogenic) origin can be suggested.

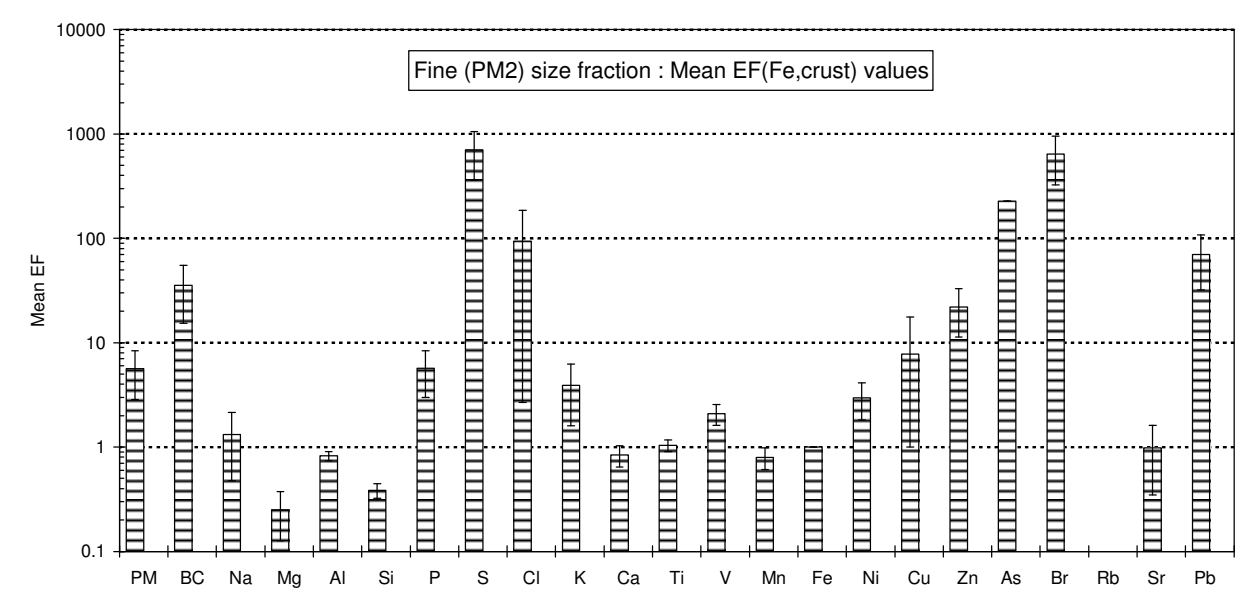

Fig. 2. Mean crustal enrichment factors for the fine size fraction aerosols in Morogoro. The error bars denote 1 standard deviation.

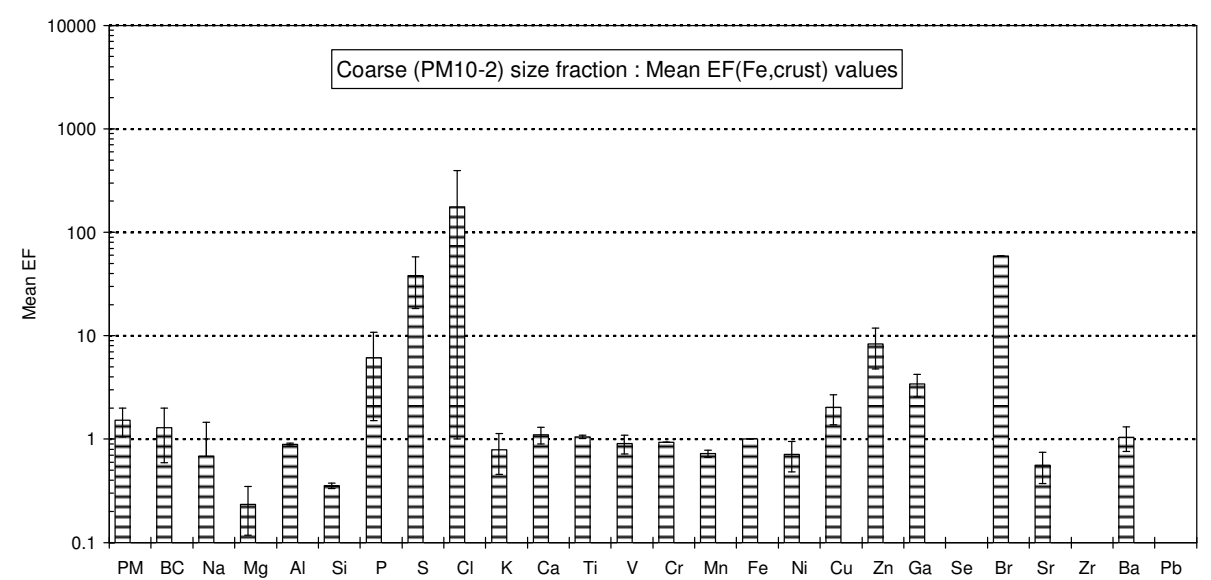

Fig. 3.Mean crustal enrichment factors for the coarse size fraction aerosols in Morogoro. The error bars denote 1 standard deviation.

Air Mass Climatology: Air masses during their motion can be loaded with particles and gases from natural and anthropogenic sources. To examine the effect of long-range transported air masses on PM and elemental components at Morogoro, air mass back trajectory analyses were performed daily during the sampling period (March - April 2006) using the Hybrid Single-Particle Lagrangian Integrated Trajectory model (HYSPLIT version 4) (Draxler and Rolph, 2003) utilizing the Final Model Run (FNL) meteorological data set. Five-day isentropic backward trajectories were computed for arrival levels of 100, 500, and $1500 \mathrm{~m}$ above ground level (agl) at 00:00 and 12:00 UTC arrival times for night and daylight periods, respectively.

The daily air mass back trajectories for Morogoro were categorized into four different sectors (see Figures 3). The allocated sectors were T1 (Oceanic); T2 (Oceanic, over Madagascar); T3 (oceanic over continental, mainly through Mozambique and Tanzania) and T4 (Continental, over Tanzania, Mozambique, South Africa). Allocation to a particular sector was made using criteria similar to those used by Traub et al. (2003). In the 2006 wet season campaign, at Morogoro, T3 was most common sector followed by $\mathrm{T} 1, \mathrm{~T} 2$ and $\mathrm{T} 4$. 

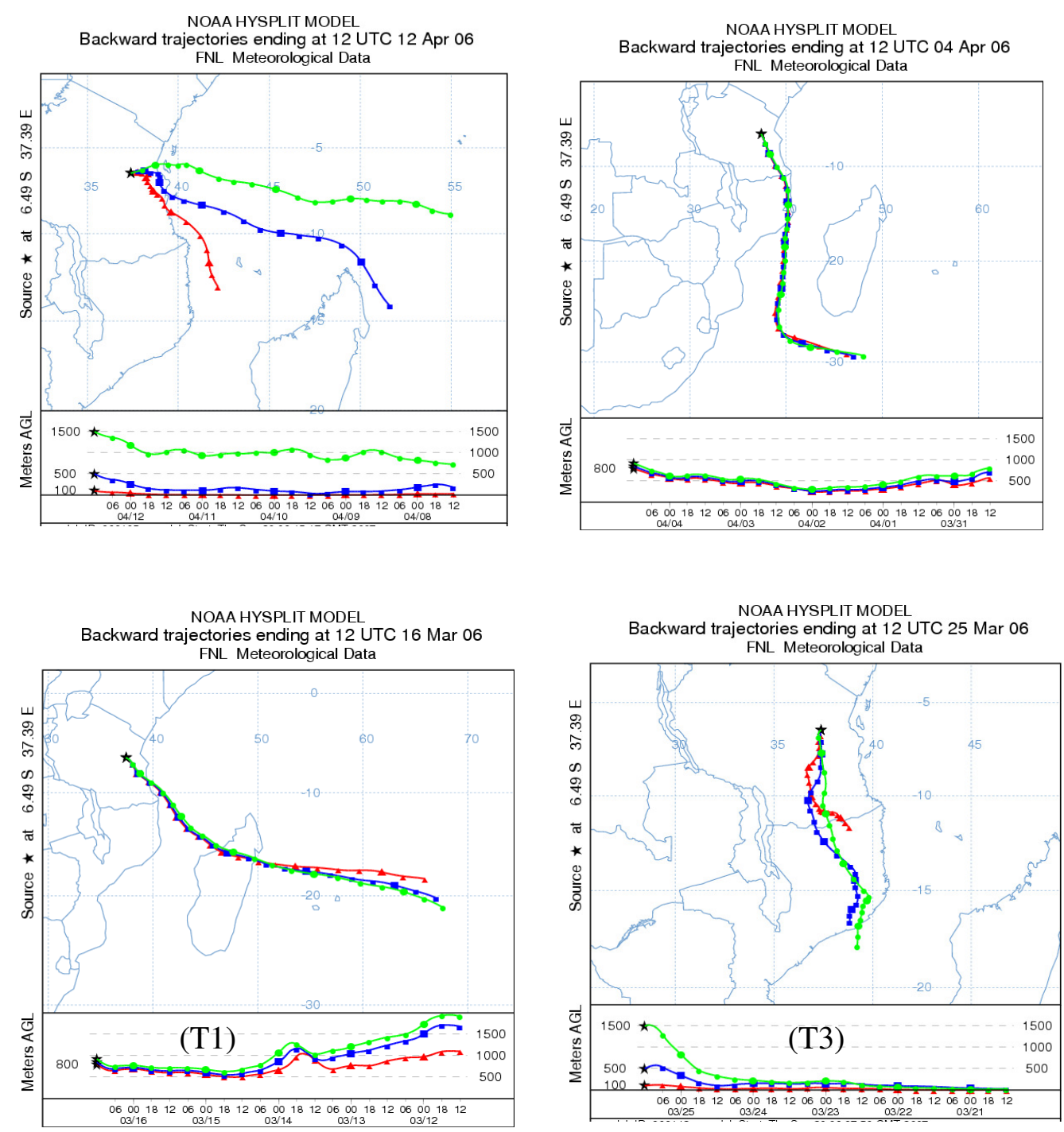

Fig 3. Typical examples of five-day back trajectories for air masses arriving at SUA Main Campus. Morogoro during the 2006 wet season sampling campaign

Conclusion: Elemental analysis of PM10 particles using PIXE analysis showed the presence of major, minor, and trace elements at Morogoro atmosphere during the 2006 wet season campaign. Elevated concentrations of crustal elements ( $\mathrm{Al}, \mathrm{Si}, \mathrm{Ca}, \mathrm{Ti}$, $\mathrm{Mn}$, and $\mathrm{Fe}$ ) and the sea-salt elements $(\mathrm{Na}, \mathrm{Mg}, \mathrm{Cl}$, $\mathrm{Sr}$ ) were observed while $\mathrm{As}, \mathrm{Se}, \mathrm{Br}, \mathrm{Rb}, \mathrm{Ba}$ and $\mathrm{Pb}$ were below the detection limit. For the coarse size fraction, most elements have crustal elements EFs that are very close to one (in contrast higher EFs in the fine fraction), thus suggesting that they are attributable mainly to soil dust dispersal. The daily air mass back trajectories shows that allocated sector of oceanic origin over continental, mainly through Mozambique and Tanzania was the most common.
Acknowledgments: This research was funded by the Sokoine University of Agriculture (SUA) and Flemish Interuniversity Council (VLIR) program. The authors would like to thank Sheila Dunphy and Jan Cafmeyer for their great cooperation and help, and the NOAA Laboratory for making HYSPLIT model available to researchers all over the world.

\section{REFERENCES}

Draxler, RR; Rolph, GD (2003). HYSPLIT (Hybrid Single-Particle Lagrangian Integrated Trajectory) Model, NOAA ARL READY Website, NOAA Air Resources Laboratory, Silver Spring, MD, http://www.arl.noaa.gov/ready/hysplit4.html. 
Gatebe, CK; Tyson, PD; Annegarn, HJ; Helas, G; Kinyua, AM; Piketh, SJ (2001). Characterisation and transport of aerosols over equatorial eastern Africa. Global Biogeochemical Cycles, 15: pp. 663-672.

Hopke, PK; Xie, Y; Raunemaa, T; Biegalski, S; Landsberger, S; Maenhaut, W; Artaxo, P; Cohen, D (1997). Characterisation of the Gent Stacked Filter Unit PM10 sampler. Aerosol Science and Technology, 27: pp. 726-735.

Intergovernmental Panel on Climate Change (IPCC), 2007. IPCC fourth assessment report 2007. Cambridge University Press, London.

Maenhaut, W; Cafmeyer, J (1998). Long-term atmospheric aerosol study at urban and rural sites in Belgium using multi-elemental analysis by particle-induced $\mathrm{x}$-ray emission spectrometry and short-irradiation instrumental neutron activation analysis. XRay Spectrometry, 27: pp. 236-246.

Mason, B; Moore, CB (1982). Principles of Geochemistry, John Wiley, Hoboken, New Jersey.

Mkoma, SL; Maenhaut, W; Chi, X; Wang, W; Raes, N (2009b). Chemical Composition and Mass Closure for PM10 Aerosols during the 2005 Dry Season at a Rural Site in Morogoro,
Tanzania. X-Ray Spectrometry, 38: pp. 293300.

Mkoma, SL; Maenhaut, W; Chi, X; Wang, W; Raes, $N$ (2009a). Characterisation of PM10 Atmospheric Aerosols for the Wet Season 2005 at Two Sites in Tanzania, East Africa. Atmospheric Environment, 43: pp. 631-639.

Moloi, K; Chimidza, S; Selin Lindgren, E; Viksna, A; Standzenieks, P (2002). Black carbon, mass and elemental measurements of airborne particles in the village of Serowe, Botswana. Atmospheric Environment, 36: pp. 2447-2457.

Nyanganyura, D; Maenhaut, W; Mathuthu, M; Makarau, A; Meixner, FX (2007). The chemical composition of tropospheric aerosols and their contributing sources to a continental background site in northern Zimbabwe from 1994 to 2000. Atmospheric Environment, 41: pp. 2644-2659.

Traub, M; Fischer, H; de Reus, M; Korman, R; Heland, J; Schlager, H; Holzinger, R; Williams, J; Warneke, C; de Gouw, J; Lelieveld, J (2003). Chemical characteristics assigned to trajectory clusters during the MINOS campaign. Atmospheric Chemistry and Physics, 3: pp. 459-468. 